\section{Relationship of Ovarian Hormones to the Pyogenic Effect of Corynebac- terium pyogenes}

Rowson, Lamming and Fry ${ }^{1}$ and Lamming and Rowson $^{2}$ have reported that purulent infections rapidly become established in the uterus of the cow following introduction into the uterus of infected bull semen or cultures of $C$. pyogenes during the luteal phase of the cestrous cycle, but infections introduced into the uterus of cows in cestrus fail to become established. Using ovariectomized cows, the resistance and susceptibility of the bovine uterus to infection was shown to be due to the action of cestrogens and progesterone respectively. The possibilities suggested to account for the variation in resistance to infection include: (a) an increase in leucocyte activity during oestrus, $(b)$ an increase in antibody activity during ostrus, (c) the production in the uterus during the luteal phase of an environment suitable for rapid bacterial development. The present work is concerned with the effects of the uterine environment.

Uteri were removed at slaughter from cows and rabbits which were in the luteal phase and from cows during the follicular phase and in anoestrus, and from rabbits injected one day previously with $10 \mathrm{mgm}$. stilbœstrol and in ancstrus. Using aseptic precautions, blood samples were also collected from the rabbits by heart puncture and from the cows by bleeding from the jugular vein. Blood samples were also collected from cows during the luteal phase, in œstrus, and from pregnant cows.

The primary aim of the work was to establish whether or not the uterus of the oestrous animal contained substances which were antibacterial in action. Using aseptic precautions, the uterine mucosa of cows and rabbits was exposed and a small circle $(0 \cdot 5-2 \cdot 0 \mathrm{~cm}$. diameter) of sterile filter paper was pressed against the uterine mucosa to make a swab. Two swabs from each animal were placed on horse blood agar inoculated with $C$. pyogenes. In some cases additional swabs from cow and rabbit uteri were placed on rabbit blood agar or cow blood agar containing $C$. pyogenes. Small strips of uterine mucosa from both species were also placed in horse-, cow- or rabbit-blood agar plates with and without $C$.pyogenes. Rabbit blood was obtained by heart puncture from animals injected intramuscularly one day previously with $10 \mathrm{mgm}$. stilbœestrol ; and blood samples were obtained both from pregnant cows and those in the cestrous and luteal phases. Two or three drops of plasma, or whole blood, on separate sterile filter disks were placed on horse blood agar plates with and without $C$. pyogenes.

Preliminary results using strips of uterine mucosa and swabs of uterine fluid showed an increased zone of hæmolysis, $3-5 \mathrm{~mm}$. wide, on horse blood agar plates containing $C$. pyogenes when the tissues or swabs were taken from either a cow in the follicular phase, an anœestrous cow, or a rabbit treated with stilbœstrol. There was no zone of hæmolysis on horse blood agar plates containing $C$. pyogenes when the uterine tissue or swab originated from either an anoestrous rabbit, cows in the luteal phase or in rabbits 3-6 days post-ovulation. There were no zones of hæmolysis on horse, cow or rabbit blood agar plates without $C$. pyogenes whatever the origin of the tissue or swabs.

That a combination of $C$. pyogenes, horse blood agar and material taken from an animal during a particular phase of reproductive activity will cause increased hæmolysis is unusual and interesting. The zones of increased lysis occurred when tissues or blood plasma were taken from animals which, on the basis of the earlier work, would be expected to be resistant to experimental uterine infections. It seems probable that these zones of increased lysis are not associated with more active growth of the test organism. That the zones of increased lysis can be demonstrated using blood plasma as well as uterine swabs and uterine tissue suggests that a general physiological effect may be present. Work is continuing to decide whether the effect is due to specific antagonistic or stimulatory effects of the sex hormones, or their analogues.

\section{George Eric Lamming Alan Seaman Matcolm Woodbine}

School of Agriculture, University of Nottingham. Sept. 22.

${ }^{1}$ Rowson, L. E. A., Lamming, G. E., and Fry, R. M., Nature, 171, 749 (1953); Vet. Rec., 65, 335 (1953).

${ }^{2}$ Lamming, G. E., and Rowson, L. E. A., Proc. Roy. Soc. Med., 46. 387 (1953).

\section{Competition among Wild Rats}

OBSERvations in the field and in large enclosures have shown that feral rats (Rattus norvegicus Berkenhout), unlike albinos of this species, display, in a highly developed form, both territorial and other types of competitive behaviour ${ }^{1-3}$. Interspecific competition, between $R$. norvegicus and $R$. rattus L., has also been directly observed ${ }^{2}$. These studies have, however, thrown little light on the exact circumstances which evoke competition, or on the precise nature of the behaviour involved.

Colonies of both species of rats have been maintained in cages of about 1 cu.m., with attached nest boxes. Cinematograph films have been taken of some colonies in a cage with a glass front. The rats were marked with a depilatory. In these conditions, groups of adult males of both species, trapped in Glasgow or bred from rats so trapped, have lived for up to twenty-two weeks without mortality, and usually without injury. Generally, several individuals slept together in a nest box, without distinction of species. Thus competitive behaviour is not necessarily evoked. by the presence of another male, or by a member of a closely related species. In these experiments all the males were introduced, at the same time, into an unfamiliar cage. However, as described also elsewhere ${ }^{2}, R$. norvegicus males newly introduced into an established colony were often persecuted by members of their own species : some died within a few days. This type of competitive behaviour is evidently the result of the establishment of a territory. Females of both species will also live together without conflict. Non-parturient females differ from males, however, in not showing territorial behaviour.

$R$. norvegicus males, put in cages together with females of the same species, fight vigorously. In the first of such experiments only one (the heaviest) out of six males survived after eleven weeks. Control males, litter mates of the experimental animals, kept singly in small cages each with one female, showed no mortality; these pairs have produced many viable litters. Females do not fight as males do, and they nearly always survive the experiments without injury. They readily become pregnant during the 